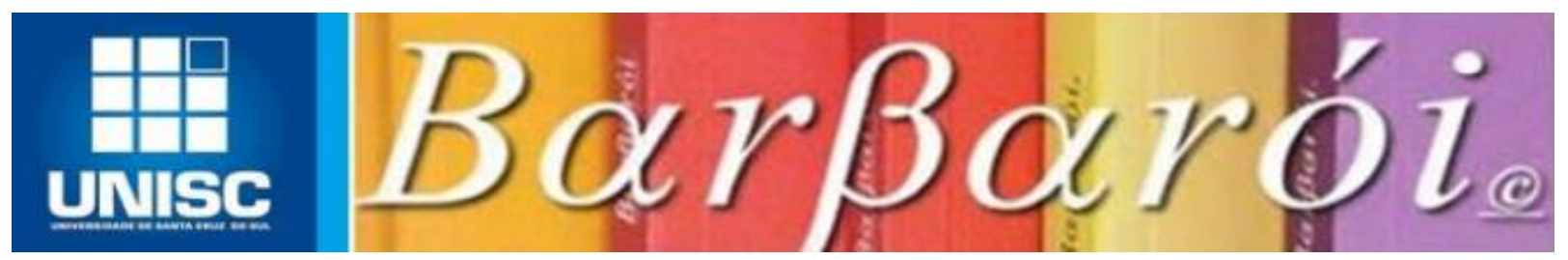

\title{
TRABALHO DE CAMPO DA PSICOLOGIA SOCIAL EM UMA LAN HOUSE: INCLUSÃO OU MEDIAÇÃO DIGITAL?
}

\author{
DOI: http://dx.doi.org/10.17058/barbaroi.v51i1.6434 \\ Maria de Fátima Aranha de Queiroz e Melo \\ Universidade Federa, de São João del-Rei - UFSJ-Brasil \\ Márcia Oliveira Moraes \\ Universidade Federal Fluminense - UFF - Brasil
}

\section{RESUMO}

Este artigo tem o propósito de problematizar o que comumente tem sido chamado de "inclusão digital", apresentando o fenômeno a partir de três referências: o trabalho de campo da Psicologia Social realizado em uma Lan house instalada num campus de universidade; as contribuições da Teoria Ator-Rede como referencial teóricometodológico; e as contribuições de autoras que defendem a postura ético-política de um pesquisar com, e não sobre os participantes de uma investigação. Esta problematização ocorre de forma reflexiva ao longo de um período em que oficinas mediadas por computadores com acesso à internet têm sido frequentadas por diferentes públicos, impondo a necessidade de engendrar estratégias variadas no que atualmente se entende como uma "mediação". Considera-se que as tecnologias digitais podem ser potencializadas para ações imprevistas, ora revelando-se como territórios de subjetivação, ora mostrando-se como disseminadoras de padrões.

Palavras-chave: Tecnologias de Informação e Comunicação; Teoria Ator-Rede; Inclusão Digital;

\section{INTRODUÇÃO}

A instalação de uma Lan house num campus universitário, em articulação com as políticas públicas de inclusão digital, deflagrou a necessidade de problematizar a maneira de nomear e conduzir esse processo nos projetos de extensão e pesquisa propostos para esse espaço, levando a afirmar o que se pode chamar de mediação digital ao invés de uma inclusão digital, tendo como referências trabalhos que colocam em questão a posição de pesquisadores e pesquisados. Num primeiro momento, é apresentado um breve panorama do que se tem pretendido como processo de inclusão digital no Brasil e busca-se descrever o processo de instalação da Lan house como um Ator-Rede. Em seguida, as oficinas de 
mediação digital foram tomadas em seu papel clínico e político como um campo da Psicologia e foram analisadas suas interações segundo as concepções de Latour. Ao final, fez-se a defesa de que, como extensionistas, o papel desempenhado tem sido de mediar, e não de incluir. Como pesquisadores, defende-se que a postura é pesquisar com, e não mais sobre aqueles que são inspiradores na produção de conhecimento.

Diante do crescimento e disseminação das tecnologias de informação e comunicação pelos vários setores da vida contemporânea nas últimas décadas, a inclusão digital no Brasil, seguindo o exemplo de outros países, passou a ser palavra de ordem e alvo de políticas públicasi ${ }^{\mathrm{i}}$ Operações bancárias, trocas de mensagens, manuseios de máquinas, preenchimentos de formulários, controles de estoques, solicitações de documentos, buscas de informação e contatos pessoais relacionados ou não à vida do trabalho, entre outras ações, passaram a ser regidos pelo uso de computadores inseridos em larga escala nos espaços de convivência das pessoas. A suposta facilitação de tarefas que as tecnologias digitais produziram também criou um divisor de águas entre aqueles que têm o seu manejo e aqueles que ficam à margem desse processo com menos chances de serem assimilados pelo mercado de trabalho ou mesmo de "existirem" socialmente num ciberespaço. Por essa razão, setores da sociedade, órgãos públicos e ONGs se interessam cada vez mais em oferecer o acesso a essas tecnologias, tendo como principal motivo o fato de que a exclusão digital poderia promover também a exclusão social, reduzindo, por exemplo, as chances de alguém ser incorporado ao mercado de trabalho sem que tenha um e-mail de contato ou sem ter acesso a sites de empresas.

Silva e Gushken (2009) destacam que, além do tripé Governo - Setor Privado Sociedade Civil, deve-se pensar nas universidades como entidades educacionais, que têm o compromisso de capacitar e formar recursos humanos. A Lan house que foi foco do trabalho, instalada num campus de universidade, a princípio sintonizada com essa necessidade, se mantem comprometida com missões semelhantes àquelas atribuídas às bibliotecas e brinquedotecas; ou seja, de ser um espaço para acesso gratuito - não a livros ou brinquedos - mas às novas tecnologias para aqueles que não têm a oportunidade de têlas no seu cotidiano.

A Lan house foi concebida para funcionar como um laboratório de extensão e pesquisa na Universidade Federal de São João del Rei tomando as oficinas mediadas por computadores como espaços de experimentações e misturas. Para os frequentadores da Lan, experimentação de si e de papéis e estratégias na interação com máquinas e humanos, em misturas ainda não tentadas antes, foram as marcas do que se designa como 
um laboratório. Para os pesquisadores, buscando diminuir o hiato de uns grupos em relação a outros, causado pelo surgimento das tecnologias digitais na sociedade, foi oferecida a oportunidade para investigar o que e como essas tecnologias produzem na construção das identidades e nas formas de socialização dos grupos frequentadores, seguindo um fenômeno em pleno acontecimento. Acrescentando o espaço da Brinquedoteca, já existente como laboratório para investigação acerca da ludicidade sob vários olhares disciplinares, a Lan house tem funcionado, desde então, como local onde as práticas lúdicas se processam com a mediação dos computadores, permitindo aos integrantes do projeto verificar e acompanhar muitos dos efeitos por eles produzidos através dos jogos eletrônicos e acesso à internet.

Voltado para projetos de extensão e pesquisa, o trabalho desenvolvido na Lan house teve como objetivo inicial estar em consonância com as expectativas de uma política de inclusão digital de grupos que compõem uma ampla parcela da população brasileira, que ainda não teve acesso às tecnologias de informação e comunicação em seu cotidiano. Entretanto, o que se tem chamado de "inclusão digital" passou a ser problematizado à luz de referências da Psicologia Social com inspiração na Teoria AtorRede. Segundo Moraes (2003, p. 4),

\footnotetext{
[...] em lugar de vínculos entre homens, trata-se de seguir os vínculos entre humanos e não humanos e mais do que isso trata-se de perguntar pelos efeitos que tais vínculos produzem. [...] Então uma Psicologia Social não é aquela que lida com o homem em sociedade, mas aquela que acompanha, segue o processo de fabricação do homem e dos objetos.
}

Esse entendimento da Psicologia Social como o acompanhamento de como se fabricariam homens e objetos em constante processo de transformação mútua particularmente foi interessante quando se tomou como foco o que se estava produzindo na relação entre os participantes das oficinas juntamente com as máquinas, seus softwares, o acesso à internet e todos os elementos componentes do espaço da Lan.

Outras questões foram se tecendo ao longo do trabalho, principalmente na maneira como eram conduzidos os encontros na Lan house. O modelo "aula de informática" foi se revelando improdutivo e passou-se a assumir a lógica das oficinas como um espaço de trabalho, onde se produzem fatos, como será visto mais adiante.

Os primeiros grupos a frequentar as oficinas, em 2008, foram de alunos de uma escola pública, que tinham pouco ou nenhum contato com computadores. A inclusão digital dos alunos era uma das metas do plano estratégico esboçado pela diretora dessa 
escola, vizinha ao campus da universidade, com quem foi estabelecida uma primeira parceria, atendendo à demanda de uma política de educação já indicada pelo MEC, inclusive com vistas à construção de um laboratório de informática em espaço contíguo à biblioteca da escolai ${ }^{\text {ii }}$. Com o passar do tempo, verificou-se que as demandas endereçadas às oficinas na Lan house não se limitavam às situações de aprendizagem deflagradas na escola (as pesquisas sobre determinados assuntos e as habilidades com editor de texto, entre outras). Ao contrário das expectativas escolares, as demandas dos participantes podiam ser mais intensamente verificadas para suprir a necessidade de contato e pertencimento às redes sociais ou à prática de jogos eletrônicos. Outros grupos demandaram a participação nesse espaço e, para cada um deles, foram observados processos muito peculiares pouco atrelados às necessidades de seus campos de trabalho atuais - no caso de adultos - ou futuros - no caso de crianças e adolescentes. Foi assim que o grupo de trabalho passou a se interessar pelo que era interessante para eles, os frequentadores, abdicando do que, supostamente, deveria ser uma "inclusão digital" com objetivos definidos por antecipação aos sentidos que dariam a essas práticas. Jogos eletrônicos, funk, músicas e filmes eram as escolhas frequentes entre os mais jovens. Tutoriais do Youtube de "como fazer", Google Maps, redes sociais e pesquisa no Google por assuntos variados eram atividades preferidas dos grupos de adultos e idosos.

\section{UMA LAN HOUSE NO CAMPUS}

Como todo e qualquer fenômeno, a Lan house se constitui como um ator-rede, uma vez que um ator é sempre uma rede, nunca age sozinho, e uma rede sempre se pontualiza como um ator. Segundo autores como Law (1992), Latour (2013) e Venturini (2009), seres (humanos e não humanosiii), máquinas, instituições sociais, organizações, conhecimento produzido, enfim, tudo o que existe pode ser visto como um produto ou efeito de uma rede de materiais heterogêneos num agregado aberto e dinâmico passível de se diferenciar com a mudança de posição e/ou a entrada de novos elementos. A Lan house configurou-se como um fato/artefato composto por uma rede que mobilizou mais $\operatorname{actantes}^{\mathrm{iv}}$ do que apenas projetos, máquinas e usuários, performando mais e mais fatos.

A chegada de uma Lan house no campus foi um processo cheio de brechas e desvios não só durante a sua instalação - com todos os percalços encontrados para que esse espaço contemporâneo fosse recriado no ambiente universitário, modificando pautas técnicas vigentes na instituição -, assim como ao longo de sua execução, mobilizando 
uma gama de actantes muito heterogêneos na produção de efeitos nem sempre previstos. De acordo com Latour (2001), os objetos técnicos ou artefatos, tais como os fatos científicos, trilham um caminho bastante tortuoso; são resultantes de uma rede traçada por coletivos de humanos e não humanos, que coadjuvam para o seu aparecimento. A Lan house e sua instalação no espaço da Universidade Federal de São João del Reinão fugiram a essa lógica, uma vez que, longe de um caminho reto, seus idealizadores foram confrontados com um labirinto de problemas e possibilidades, que estavam distantes de uma situação de consenso. Problemas técnicos, muitas vezes, exigiram soluções diplomáticas, enquanto problemas humanos, por vezes, esbarravam em questões técnicas.

A instalação deste laboratório a que se chamou de Lan house foi, o tempo todo, repleta de controvérsias de diversas ordens envolvendo humanos, não humanos e híbridos. Não só o espaço físico produziu curiosidade e estranhamento em setores da comunidade, como o acesso de novos públicos deslocou interesses e controvérsias. Os interesses logo se manifestaram não só por parte de alunos, como de funcionários e adolescentes de comunidades próximas, que já frequentavam o campus por participarem de outros projetos desenvolvidos pela universidade. No que se refere às controvérsias, alguns preconceitos tiveram que ser ultrapassados, buscando afirmar: que o espaço não seria um dispersor da vida acadêmica; que o fato de haver computadores em rede com uma "porta" externa não significaria vulnerabilizar a segurança da rede da universidade, atraindo um exército de hackers; quanto ao acesso de novos públicos, que a chegada de crianças e adolescentes buliçosos não atrapalharia as aulas dos diversos cursos; que as rampas para deficientes físicos com suas cadeiras de rodas e muletas não roubariam as escassas vagas já deficitárias para carros no estacionamento do campus; que, sendo mais vulneráveis, os grupos de idosos e crianças, para transitar no acesso à Lan, teriam necessidade da instalação de quebra-molas, a fim de garantir sua segurança, o que retardaria os motoristas mais apressados na rotina de acesso aos seus locais de trabalho. Com o tempo, entretanto, e não sem reclamações, o dia a dia do campus foi se acomodando a esses novos públicos, que fugiam do padrão de excelência costumeiramente esperado daqueles que circulavam por suas dependências.

\section{AS OFICINAS DE MEDIAÇÃO DIGITAL}

$\mathrm{Na}$ busca de um modelo de atuação, as oficinas foram concebidas como um dispositivo experimental tal como entendido por Despret (1996). Conforme a autora, na 
atividade de pesquisa, chamou-se de dispositivo experimental uma situação que distribui as atividades de maneira inventiva de modo que, ao estabelecer relações onde elas não existiam, propicia a emergência da novidade, tornando-se um lugar de construção e de agenciamento entre pesquisador e pesquisado. Da Lan house, enquanto um dispositivo, fazem parte os participantes das oficinas, os monitores, os professores-supervisores, o laboratório com suas máquinas, os softwares, a internet com suas falhas, as pautas e parcerias institucionais, os comitês de ética e os acessos ao campus entre outros actantes que interferem nas interações. A mediação aqui pode ser pensada em vários níveis e campos, performada/encenada por vários atores, da mesma maneira como se pensa o dispositivo das oficinas, ele próprio um mediador: um arranjo heterogêneo que ativa todos, sendo performativo ao produzir efeitos inéditos.

A concepção de oficina que, primeiramente, influenciou o trabalho foi a de Afonso (2013), para quem esses encontros não têm a pretensão de se configurar como terapia stricto sensu, mas que, nem por isso, deixam de produzir efeitos sentidos como terapêuticos. De fato, observou-se que a situação de faz-de-conta virtual produz um distanciamento em relação à vida real, amenizando a ansiedade eliciada por situações desafiadoras de estratégias de sobrevivência nos mais variados níveis.

Outra influência para a proposta das oficinas encontra-se no trabalho de Kastrup (2012). Na perspectiva da autora, as oficinas, enquanto espaços de encontro, convivência e aprendizagem, assumem algumas particularidades quando mediadas pelos computadores em rede, que, ao se prestarem a ser um equipamento coletivo de subjetivação, permitem um funcionamento diferenciado, uma vez que "múltiplo, disperso, a-centrado, que reúne pessoas e coisas que a compõem" (KASTRUP, 2012, p. 175). O extensionista, sempre potencialmente um pesquisador, é aquele que faz a conexão entre os participantes e entre estes e as máquinas. Como tal, estará imerso e sensível às demandas dos participantes, para que estes tenham nas oficinas um tempo-espaço de elaboração, respeitados os seus limites. As intervenções se dão no sentido de melhor entender os movimentos de cada jogador em sua trajetória particular.

As oficinas na Lan house acontecem segundo os acordos firmados pelas demandas e disponibilidades de horários dos grupos ${ }^{\mathrm{v}}$ e estagiários/bolsistas ${ }^{\mathrm{vi}}$, na frequência de pelo menos uma vez por semana, com uma hora e meia a duas horas de duração. Os encarregados de conduzir as oficinas (bolsistas e estagiários) fazem registros num diário de campo informando quem foram os participantes, quais as propostas para aquele dia, qual o plano que efetivamente foi cumprido ou negociado, qual a dinâmica verificada no 
grupo e quais os resultados, as dificuldades encontradas e as estratégias para resolver as dificuldades. Esses registros são compartilhados para as equipes que trabalham com os outros grupos mediante o envio de um relatório aos signatários do Yahoo Groups utilizado para nossas comunicações. Os informes são recuperados durante as reuniões de supervisão semanal com os professores orientadores para discussão de seus pontos controversos.

Durante e após cada oficina, ocorre uma conversa de cunho informal entre participantes e pesquisadores, para mapear as escolhas feitas durante as atividades, no sentido de entender como estas estão sendo articuladas com as necessidades de experimentação de si e das relações estabelecidas com os elementos de um jogo, de um software ou das redes sociais por parte de cada jogador. Simultaneamente às oficinas, bolsistas e estagiários também empreendem uma imersão nos jogos, nos softwares e na literatura produzida para mapear as possibilidades de cada proposta de oficina como elemento subjetivador, além de pesquisar sites e materiais, que ajudem a seguir e entender o desenvolvimento das estratégias utilizadas na rede de possibilidades, as quais as tecnologias oferecem ao desafiar destrezas e/ou dublar as situações da vida real. Nesse exercício, muitos deles descobrem/aprendem estratégias que antes não lhes eram conhecidas, ampliando também suas possibilidades.

Esses encontros não só permitem observar e registrar as falas e as impressões dos participantes durante e após as atividades - uma vez que é nesse tempo-espaço de convivência que os participantes poderão ser acompanhados e entendidos em seus movimentos -, como oferecem aos participantes a oportunidade de construir um entendimento e uma narrativa muito peculiar sobre a sua trajetória nas oficinas. Para os pesquisadores, torna-se possível descrever e verificar as potencialidades das atividades com jogos, redes sociais e habilidades com o computador como elementos que compõem o fluxo identitário dos jogadores, nas suas possibilidades de socialização e na construção de aprendizagens incorporadas à sua bagagem vivencial.

Como grande parte do público frequentador se encontra em situação de vulnerabilidade social, assumiu-se o compromisso ético de que as oficinas sejam uma ferramenta de subjetivação positiva e de experimentação de opções em relação à maneira de ser e estar no mundo dos participantes, onde seus limites e potencialidades sejam percebidos e manejados com responsabilidade e cuidado pelos pesquisadores. Apesar de a demanda pelas oficinas ter partido dos próprios grupos/instituições, no caso do trabalho desenvolvido em parceria com menores, egressos da APAE e idosos, providências foram 
tomadas no sentido de obter, das figuras tutoras, a permissão para realizar o trabalho.

\section{AS OFICINAS DE MEDIAÇÃo DIGITAL EM SEU PAPEL CLÍNICO E POLÍTICO}

Para pensar no papel do mediador, nas oficinas da Lan, Kastrup (2012) ajuda a tomá-las como um espaço de trabalho para a Psicologia (é comum os alunos perguntarem o que a Psicologia tem a ver com uma Lan house). Tentou-se fugir da oficina entendida como um mero passatempo, curso profissionalizante ou destinada a fins educacionais. A proposta é pensar a oficina em seu papel clínico e político de subjetivação no contexto de uma pesquisa-intervenção, por meio do acompanhamento de processos que ali ocorrem. A autora defende as oficinas como espaços coletivos de fazer, de construir, de experimentar e de inventar junto, quando todos possam ter a chance de aprender: usuários, estagiários, pesquisadores. Para as pessoas que participam, as oficinas podem ser tomadas como uma referência devido à regularidade dos encontros que oferecem o ritmo e o sentimento de estar em "um lugar seguro para a criação e expansão de territórios existenciais" (KASTRUP, 2012, p. 174). Quando fala de oficinas mediadas por computadores, a autora considera que a aprendizagem se dá por fluxos muitos variados, nos quais as subjetividades investem e, reciprocamente sobre elas, esses fluxos também produzem diferenciações, trazendo uma rede de conexões (com pessoas, coisas, instituições e saberes) e convergindo para os fenômenos que ocorrem nas oficinas. Nesse campo, a Psicologia se configura como um campo de interfaces fluidas, em que fronteiras transbordam para outros domínios, ultrapassando limites antes demarcados. Com esta abordagem, o que se realça é um pesquisar com, ao mesmo tempo uma metodologia e uma política de pesquisa, em que os participantes dão ideias e interferem no campo de trabalho, trazendo suas narrativas e perturbações em situações de imprevisibilidade. Nesse caso, é importante questionar como um estagiário/bolsista nos projetos desenvolvidos pode ser um elemento provocador de diferenciação na rede de acesso e qual o papel dessa figura que compõe com as máquinas e aplicativos essa rede de “inclusão" recíproca que se poderia chamar de mediação: um mediador de multiplicidades, segundo Kastrup. 


\section{AS INTERAÇÕES NAS OFICINAS DA LAN HOUSE VISTAS SOB A ÓTICA DA TEORIA ATOR-REDE}

As oficinas na Lan house são compostas por um agregado de relações mediadas por humanos e por uma multidão de híbridos. Às interações, cuja ação se dispersa pelos vários actantes que compõem uma cena, Latour (1994) chamou de "enquadradas" por se darem em quadros que agregam pessoas e matérias performando espaços e tempos. Definiu essas interações de forma performativa ${ }^{\text {vii }}$, e não ostensiva ${ }^{\text {viii }}$, apontando o seu avesso; ou seja, o que elas não são.

De acordo com o autor, as interações não são homogêneas, pois reúnem uma multiplicidade de participantes, que não carregam as mesmas qualidades e sequer são antropomórficos. Nas oficinas da Lan, como em qualquer interação, a heterogeneidade entre os participantes é uma característica marcante pela presença massiva de humanos, de máquinas, de softwares, de pautas institucionais, por vezes de animais que acompanham os participantes, plantas e outros elementos, que compõem o cenário do campus, onde se encontra a Lan. As oficinas, por vezes, se expandem para além da sala em que estão os computadores, ocupando outros locais do campus para a tomada de fotos, a execução de uma receita para o lanche ou a composição de um artesanato aprendido no Youtube.

As interações que acontecem nas oficinas também não são sincrônicas, ou seja, não carregam a mesma temporalidade, pois trazem elementos oriundos de períodos de tempo diferentes. Diz Serres (1999) que qualquer acontecimento na história é multitemporal, porque a ideia de contemporâneo remete, ela mesma, simultaneamente, a algo que é do passado e aponta para um tempo que ainda está por vir. E é o que de fato se pode verificar quando se toma todo o trajeto que permitiu o atual estágio dos computadores pessoais com suas interfaces, as peças de mobiliário que compõem a sala e os artefatos que são carregados e que são dotados das mais variadas lógicas concebidas em períodos diferentes. Cada objeto carrega uma série de componentes, cuja origem se deu em períodos diferentes, sendo agregados em composições que, à primeira vista, parecem homogêneas, mas não são. Algo que produz estranhamento e/ ou admiração nas pessoas, que não têm muita intimidade com os computadores, é o fato de que, pelas máquinas em rede, tempos e espaços diferentes podem ser alcançados: ações em tempo real, no contato direto com interlocutores que estão em outras máquinas, e os rastros 
deixados por outros usuários que passaram pela mesma máquina ou pela rede acessada. O futuro também se insinua como possibilidade na medida em que o inédito se torna viável; primeiro, em desejo e imaginação; depois, na concretude da ação, que se tornou possível com a mediação da técnica. Através dos jogos de papéis online, os vários jogadores se movem entre tempos ficcionais, que misturam cenários do passado e paisagens futuristas. Adolescentes de uma Casa Lar, jogando The Sims, se projetam num futuro ora idealizado, ora num passado carregado de situações penosas, que arriscam relatar aos poucos no faz-de-conta do jogo.

As interações também não são sinópticas, nem sempre mostrando aos olhos todas as entidades que participam do evento das oficinas. Há elementos que só se tornam "visíveis" quando eles faltam/falham. É o caso da internet ou da energia elétrica, sem os quais a oficina não aconteceria, mas que só ganham relevo no momento em que se tornam ausentes. O remédio tomado, que produz sonolência ou agitação, não pode ser visto, mas produz efeitos no participante, que não consegue o manejo adequado para fazer seus acessos à máquina e à internet. Da mesma forma, outros elementos que não estão visíveis interferem na performance dos participantes: o par de óculos esquecido em casa, para quem precisa dele para enxergar a tela; o filme, que não carrega e produz frustração; e a senha do e-mail/Facebook, que ficou registrada num papelzinho amassado e jogado no lixo ou esquecido em alguma gaveta de casa. Todos são elementos atuantes, embora ausentes, que produzem efeitos nos participantes das oficinas, mas nem sempre podem ser contabilizados no campo das coisas capturadas pelo olhar ou pela memória.

Nenhuma interação é isotópica, agindo somente em um lugar e num determinado momento. Quando as interações acontecem, elas misturam actantes heterogêneos, que não estão presos à cena em questão, podendo ter procedências outras, que não, exclusivamente, o lugar onde os encontros acontecem. Essa é uma condição das mais marcantes quando se fala de vida online e vida offline, dos deslocamentos pelo ciberespaço e da condição de ubiquidade experimentada nas interações feitas com interlocutores que se encontram em outros espaços, seja por e-mail, seja por Skype e Facebook entre outros. Ilustrativos são os casos de pessoas em lugares distantes, que se reúnem em videoconferência para avaliação de um trabalho, de músicos que tocam numa mesma banda apesar de estarem a quilômetros de distância ou de familiares que se "encontram" em festividades em contatos mediados por uma tela. A "mágica" da ubiquidade proporcionada pela internet nas interações quase presenciais, mesmo a distância, gera expectativas inflacionadas por parte de alguns dos usuários da Lan. Numa 
oficina para idosos, uma senhora surpreendeu os estagiários pedindo para que lhe mostrassem, em tempo real, a procissão de Nossa Senhora do Carmo, à qual ela não tinha podido comparecer, colocando a monitora impossibilitada de atender ao pedido devido às limitações do momento: não havia ninguém com uma câmera e/ou um celular com quem se pudesse manter contato na procissão e também não havia, para acessar pelo Youtube, nenhum vídeo já divulgado pela TV mostrando o evento ainda em curso.

As interações não são isobáricas; isto é, nem todos os participantes das interações participam delas com igual capacidade de imprimir pressão sobre os demais: alguns participantes se impõem com mais força do que outros. Há momentos em que os elementos se comportam de acordo com o que se espera deles e não produzem perturbações, sendo, nesse caso, considerados como intermediários. Para quaisquer outros que exerçam algum tipo de pressão que altere o fluxo dos acontecimentos num evento, Latour (2006) chamou de mediadores ${ }^{\mathrm{ix}}$. Os intermediários são previsíveis, fazem parte do esperado e, nessa condição, ficam imperceptíveis. Mas podem se transformar em mediadores no momento em que fazem com que a ação bifurque bruscamente de forma inesperada.

Nos momentos em que fazem uma interferência decisiva para mudar o curso da ação, em que a pressão se concentra em determinados actantes, é aí que eles têm o poder para manter, interromper, modificar. Mas essa pressão, longe de estar concentrada em alguns, pode se revezar entre os vários mediadores do evento, nem sempre presentes, ao mesmo tempo, no mesmo lugar. Casos em que intermediários se transformam em mediadores nas oficinas são aqueles em que um elemento falha nas suas funções e assume o poder de inviabilizá-las. Exemplo comum é um computador que não liga ou que não se conecta na internet, uma chave que some e impede a entrada das pessoas na Lan, a van que falhou no transporte dos participantes ou um acesso inadequado pelo estacionamento que não permitiu que uma cadeira de rodas se deslocasse para chegar à sala.

Sabe-se que um intermediário é um elemento cujos efeitos já são conhecidos e previsíveis, ao contrário dos mediadores, de quem não se pode controlar os efeitos nem sempre conhecidos. Latour (2012), em entrevista publicada por Lemos (2013, p. 274275), diz que “a diferença 'mediadores-intermediários' não é uma diferença conceitual, porque, evidentemente, não há apenas intermediários. [...] São conceitos sempre localizados que dependem, de alguma forma, do local onde estamos situados". Um intermediário de hoje pode ser um mediador amanhã, e vice-versa, num jogo de figura e fundo, que pode virar a qualquer momento, alternando o poder entre os participantes em 
função do que eles podem facilitar ou obstruir na ação de que tomam parte. O poder não paira sobre os actantes à espera de encarnação ou é um atributo prévio de alguns em detrimento de outros, mas uma resultante da concentração de forças em determinados nós da rede sempre passível de mudança.

No caso da Lan, o que se deseja para que as oficinas aconteçam é que as máquinas e a conexão com a internet possam ser boas intermediárias, realizando o que é esperado delas, sem produzir perturbações. Quando esses elementos falham em seus papéis, passam a ser mediadores com efeitos nem sempre desejáveis. Em relação aos oficineiros, esse papel também não é sempre o mesmo: tanto podem ser intermediários, mantendo-se como testemunhas das experimentações dos participantes e atendendo às suas demandas sem produzir mobilização de novas estratégias, como podem ser mediadores, provocando-os para se aventurarem de maneiras diferentes no uso das máquinas e seus softwares.

\section{INCLUIR OU MEDIAR?}

Defendia-se, no início do projeto, que, com as oficinas de "inclusão digital", além de buscar diminuir o hiato causado pelo surgimento dessas tecnologias na sociedade, seria possível ter um laboratório para investigar o fenômeno da inclusão digital em pleno acontecimento numa condição ainda distante do que Latour (2001) definiu como "caixa preta”. A ideia de caixa preta, para esse autor, é bem diferente daquela postulada pelo behaviorismo, que toma a caixa preta como aquilo que não se precisa conhecer, sendo meramente um espaço intermediário entre estímulo e resposta. Para a Teoria Ator-Rede, o conteúdo de uma caixa preta é exatamente o que vale a pena conhecer quando se instala uma controvérsia, quer esta aconteça antes do seu fechamento ou quando é levantada como motivo para reabri-la.

O processo, que a princípio foi chamado de inclusão digital, está sendo tomado como uma caixa aberta, pois, apesar de parecer um consenso a sua importância, ainda não são claras as maneiras pelas quais as pessoas se sentem afetadas pelas novas tecnologias de informação e comunicação, como a elas aderem e de que forma incorporam seus usos. A Lan house tem sido cenário para por à prova algumas concepções circulantes sobre esse processo, abrindo vários níveis de controvérsia: trata-se de uma "inclusão" ou de uma "mediação" o que é feito nas oficinas? Por que, para que e para quem ela acontece? Quais efeitos são produzidos nas vidas das pessoas a partir desse contato com as ações 
desenvolvidas em parceria com computadores e outros participantes do grupo? Subjacente a estas, outras questões que circulam dentro e fora da academia continuam a provocar a necessidade de investigação: o que se passa e o que fica no trânsito entre vida online e vida offline? As interações homem-máquina põem em xeque uma oposição ou colocam em cena uma parceria? A internet aproxima ou afasta as pessoas? É massificante enquanto lazer ou abre a possibilidade para novos territórios existenciais? Para além deste jogo de "ou isto, ou aquilo", considera-se que as possibilidades não se esgotam nos extremos das contendas, mas assumem configurações muito variadas para o seu entendimento, produzindo uma miríade de respostas.

Resgatando o exercício feito no início dos trabalhos acerca do que a equipe responsável pelo projeto entendia como inclusão digital, foram encontradas expressões tais como: "oferecer oportunidades para que as pessoas participem do mundo das tecnologias digitais"; "tornar mais fácil algum aspecto de nossas vidas através do uso das tecnologias digitais"; "mais do que possuir ou acessar um equipamento, inclusão digital é realizar aprendizagens a partir destas tecnologias"; "tornar efetiva a participação de pessoas e grupos na rede beneficiada pelas tecnologias emergentes"; "produzir em outrem a capacidade de resolver problemas no âmbito da utilização de um computador ligado à internet"; "levar pessoas a tomar contato com uma rede"; "democratizar o acesso à informação"; "tornar indivíduos agentes de mudança a partir do manuseio de recursos tecnológicos"; "ampliar o leque de opções de trabalho e entretenimento"; e "proporcionar conhecimento técnico e conceitual para que o indivíduo se sinta parte de seu grupo social". Para os membros da equipe, o conceito de inclusão digital precisava ser questionado, assimilado, elaborado como um orientador de ações. Por essa razão, buscaram-se, a partir de leituras, observações, impressões, ao longo das oficinas e supervisões, colher, em brainstorming, de alunos e professores envolvidos no projeto, tudo que pudesse compor o que se chamaria de inclusão digital.

Ora, nas definições acima, percebe-se tanto uma linearidade da ação como uma assimetria numa relação, que confere poder a quem inclui e deixa aos candidatos à inclusão a posição de passividade, de receptores de um benefício, de alunos obedientes, no sentido mais tradicional. Buzato (2010, p. 284) converge com essa posição quando pondera sobre o fato de que aqueles que falam de inclusão acabam aderindo à perspectiva de alguém que fala “'de dentro', de algum lugar que vê como seu e como bom, correto e necessário a todos". Trata-se de uma postura, que, no final das contas, pode, de fato, levar à exclusão, porque pressupõe uma hegemonia, uma vez que "nem todos os que estão 
'fora' querem ou precisam estar 'dentro" (BUZATO, 2010, p. 284). Colocando-se numa posição de quem olha, ao mesmo tempo, de dentro e de fora do fenômeno, o autor considera a inclusão digital no mesmo espaço gerador de outras inclusões (social, educacional, profissional etc.). Ele defende a inclusão/exclusão como um fenômeno relacional, e não como conteúdo ou como essência, que, de alguma forma, mantém os fluxos do poder, preferindo, ao invés, falar de apropriação tecnológica, pois é um conceito que se aplica em diferentes escalas e em diferentes níveis de análise em diversos campos disciplinares.

A temática da inclusão digital no Brasil, já bastante abordada em seus aspectos positivos e negativos nos trabalhos de diferentes áreas como Educação (DEMO, 2005), Linguística (BUZATO, 2010), Administração (BOLZAN; REI; ESTIVALETE, 2013), Políticas Públicas (LEAL; BRANT, 2012; RODRIGUES; SIMÃO; ANDRADE, 2003), Sociologia (SOUZA, 2006), Antropologia (PEREIRA, 2007; SCALCO, 2008, 2012) e Psicologia (SANTAROSA, 2002; MARASCHIN; FRANCISCO; DIHEL, 2011; PALOMBINI; MARASCHIN; MOCHEN, 2012), entre outras, passou, desde então, a assumir um contorno diferenciado para o grupo que se ocupa dessa tarefa. Uma das conclusões a que se chegou foi a de que, independentemente do nome que seria dado ao processo, este seria sempre um devir, algo que ocorreria em níveis e que estaria sempre se atualizando em novos patamares, nunca ocorrendo de uma só vez e em definitivo.

O termo mediação foi cogitado, porque, por outro lado, remete à ideia de meio, à ideia de que o mediador é um elo na cadeia, é mais um nó na rede. A apropriação de tecnologia da qual fala Buzato (2010, p. 288) leva a pensar nas relações tecnologiaindivíduo, tecnologia-grupo, tecnologia-instituição e tecnologia-cultura. Nos trabalhos desse autor, o conceito de letramento - nesse caso o letramento digital - remete à participação em um conjunto de práticas, cujos sentidos são "gerados, disputados, negociados e transformados", sendo as práticas de letramento diversas e sempre situadas, numa relação de coprodução e recursividade. Nessa apropriação de tecnologia, entendese que os objetos técnicos são também mediadores, não podem ser compreendidos como algo em si, mas como pontos numa cadeia não prevista pelo seu inventor, operando uma espécie de desvio das ações iniciais, como algo em correlação, coengendrando-se com outras entidades, produzindo diferenças numa rede coletiva que é sociotécnica e podendo participar de um campo de construção de subjetividade ou de individuação do coletivo (ESCÓSSIA, 1999). Assim, sempre haverá brechas na maneira como as tecnologias são 
apropriadas a depender dos contextos, nos quais elas acontecem e das entidades envolvidas.

A mesma compreensão que se tem sobre as tecnologias de informação e comunicação, como mediadoras entre os sujeitos e o mundo, pode ser extensiva ao papel de um mediador entre humanos e máquinas, ambas as mediações deflagrando processos a serem investigados/construídos no trabalho de mediação digital. No percurso feito na Lan, o deslocamento necessário, de uma suposta "inclusão digital" para o que se pretende ser uma mediação digital, implica permitir abandonar o papel de um professor de informática - apresentador das ferramentas do computador e da internet - para um mediador, que busca trabalhar sobre as demandas daqueles que frequentam as oficinas e solicitam aprendizagens muito específicas e localizadas. Muitas das vezes, as ações demandadas ainda não faziam parte do rol de aprendizagens dos oficineiros e os obrigava a buscar estratégias que eles próprios desconheciam. Quem inclui quem nesse caso? Sabendo que há vários níveis/camadas a penetrar na imersão desses espaços digitais, o fato é que, de um por que incluir, passou-se a um como mediar, a um para que esse trabalho tem sido realizado e, mais que um para quem, precisamos pensar num com quem.

\section{CONSIDERAÇÕES FINAIS}

A ação de pesquisar COM é defendida aqui como uma prática que reafirma uma postura política e se torna uma maneira de dar seguimento ao que se nomeia como uma mediação digital por deixar indefinidas as fronteiras entre os lugares de pesquisador e pesquisado. Com Moraes (2014, p. 134), considera-se que o desafio de desfazer e refazer fronteiras "se engaja na aposta de fazer um mundo comum, mais heterogêneo, onde mais e mais atores contem [...] um modo de fazer pesquisa que preza pelo caráter situado daquilo que se faz com o outro no campo de pesquisa".

A partir de um olhar da Psicologia, o compromisso do trabalho é investigar como os atores entram em contato com as TICs nas suas práticas lúdicas: ignorando-as e deixando-as para outros? Aderindo a elas a partir de uma tendência homogeneizante dos meios de comunicação de massa que torna tudo plano? Incorporando-as na medida em que o acesso às TICs pode produzir uma diferenciação? A questão não seria seguir uma ou outra dessas tendências, mas pesquisar como elas operam, seguindo os atores mesmos em suas práticas de maneira localizada. Pensando sob essa lógica, passa-se a questionar sobre "quem inclui quem", em qual território existencial, pois essa foi uma provocação 
da qual não foi possível escapar. Ao passar da ideia de inclusão para a ação de mediação, assumiu-se uma causalidade em rede, que leva em conta outras agências que não só a de humanos, colocando os membros do grupo de trabalho como um dos elos de uma cadeia não linear para a produção de efeitos.

Analisar o agregado que compõe as oficinas da Lan implica, necessariamente, um lidar com singularidades. A necessidade de democratização das tecnologias digitais por meio da educação, discurso sustentado pelas políticas públicas para evitar uma situação de exclusão social ainda mais acentuada, passou à preocupação de que esta "inclusão" pudesse vir a fazer sentido, no aqui e agora da vida daqueles que participavam das oficinas, pois o observado foi que as demandas endereçadas não se limitavam às situações da aprendizagem instrumental de meras ferramentas para serem usadas na escola ou no trabalho. Podiam ser mais intensamente verificadas para suprir uma necessidade de contato e pertencimento, no caso das redes sociais; para saciar o desejo pela prática de jogos eletrônicos, na construção de destrezas; como possibilidade de comunicação e ampliação das interações, no caso daqueles que buscaram contato com familiares e velhos conhecidos pelo Facebook; como suporte de informação e lazer, no caso das pesquisas no Google e dos tutoriais do Youtube para problemas da vida diária ou para baixar músicas e filmes para um lazer ativo ${ }^{\mathrm{x}}$.

Para orientar o posicionamento em relação àqueles que desejam fazer parte desse mundo digital, chega-se ao entendimento de que se torna imperioso, como condição para este trabalho: 1. Ultrapassar o discurso de que as tecnologias de informação e comunicação são uma ferramenta indispensável no mundo contemporâneo a que todos deveriam ter acesso para não ficarem à margem; 2. Negar o discurso da inclusão como um ato piedoso para com os "excluídos"; e 3. Buscar identificar que efeitos essa “inclusão" pode assumir para além de um uso instrumental da máquina. Primeiramente, apesar de necessárias, facilitadoras e multiplicadoras de nossas possibilidades (LATOUR, 1999), as tecnologias nem sempre são ou precisam ser incorporadas por todos. Há muitas pessoas que vivem bem sem elas e têm o direito de escolher quais querem, se as querem ou não em suas vidas, se serão ou não auxiliadas por elas, pois nem sempre as entendem como um benefício, chegando a vê-las como obstáculos. Em segundo lugar, a inclusão, como um ato politicamente correto, pode ser uma falácia, transformando o processo em mais um esquema docilizador de candidatos ao mercado de trabalho ou de consumidores passivos de produtos da mídia eletrônica. Por último, as tecnologias de informação e comunicação podem ser potencializadas para ações imprevistas, ora revelando-se como 
territórios de subjetivação, ora mostrando sua face mais perversa como disseminadoras de padrões, impelindo a estudar seus efeitos.

\title{
THE SOCIAL PSYCHOLOGY FIELD WORK IN A LAN HOUSE: INCLUSION OR DIGITAL MEDIATION?
}

\begin{abstract}
This article aims to discuss what has commonly been called "digital inclusion", presenting the phenomenon from three references: the field work of Social Psychology conducted in a Lan house installed on a university campus; the contributions of ActorNetwork Theory as a theoretical and methodological framework; the contributions of authors who defend the ethical-political posture of a search with and not on the participants of an investigation. This problematization takes place reflectively over a period in which workshops mediated by computers with Internet access have been frequented by different audiences, imposing the need of engendering different strategies that we currently believe as a "mediation". It considers that digital technologies can be potentialized for unexpected actions, sometimes revealing itself to be subjectivity territories and sometimes showing up as disseminators standards
\end{abstract}

Keywords: Information and Communication Technologies; Actor-Network Theory; Digital Inclusion;

\section{EL TRABAJO DE CAMPO DE LA PSICOLOGÍA SOCIAL EN UNA CASA LAN: INCLUSIÓN DIGITAL O MEDIACIÓN?}

\section{RESUMEN}

El presente artículo tiene como objetivo discutir lo que comúnmente se ha llamado la "inclusión digital", con la presentación del fenómeno desde tres referencias: el trabajo de campo de la Psicología Social llevada a cabo en una Lan house instalada en un campus universitario; los aportes de la teoría del actor-red como marco teórico y metodológico; las contribuciones de los autores que defienden la postura ético-político de una búsqueda con y no en los participantes de una investigación. Este cuestionamiento ocurre reflexivamente en un período en el que los talleres mediados por computadoras con acceso a Internet han sido frecuentado por los diferentes públicos, imponiendo la necesidad de generar diferentes estrategias que actualmente creemos como una "mediación". Se consideró que las tecnologías digitales se pueden aprovechar para acciones imprevistas, a veces revelándose como territorios subjetividad, a veces presentándose como diseminadora de normas

Palabras-Clave: Tecnologías de la Información y la Comunicación; de Teoría del ActorRed; Inclusión Digital; 


\section{REFERÊNCIAS}

AFONSO, Maria Lúcia Miranda.. Oficinas em dinâmica de grupo: um método de intervenção psicossocial.Editora Casa do Psicólogo, 2013.

BOLZAN, Larissa; REI, Eliete; ESTIVALETE, Vânia. Processos de Inclusão Digital: Um Estudo etnográfico. IV Encontro de Administração da Informação. Bento Gonçalves, RS, 2013.

BRASIL. Ministério da Ciência e Tecnologia. Conselho Nacional de Ciência e Tecnologia. Sociedade da informação no Brasil: livro verde. Brasília: Conselho Nacional de Ciência e Tecnologia, 2000.

BUZATO, Marcelo. Cultura digital e apropriação ascendente: apontamentos para uma educação 2.0. Educação em Revista, v. 26, n. 3, p. 283-304, 2010.

DEMO, Pedro. Inclusão digital: cada vez mais no centro da inclusão social. Inclusão Social, Brasília, v. 1, n. 1, p. 36-38, 2005. Disponível em: $<$ http://revista.ibict.br/inclusao/index.php/inclusao/article/view/4/7>. Acesso em: 5 dez. 2014.

DESPRET, Vinciane. Naissance d'une théorie éthologique. La danse du cratérope ecaillé. Paris: Les empecheurs de penser em rond, 2006.

ESCÓSSIA, Liliana da. Relação Homem-técnica e processo de individuação. Aracaju, SE: Ed. da UFS; Fundação Oviedo Teixeira, 1999.

HARAWAY, Donna. Able bodies and companion species. In: meet. London: University Minesotta Press, 2008. p. 161-179.

. When Species

KASTRUP, Virgínia. Fazendo psicologia no campo da saúde mental: as oficinas de tecnologia e tecnologias sociais. In: MARASCHIN, Cleci; MOSHEN, Simone; PALOMBINI, Analice (Org.). Tecnologias em rede: oficinas de fazer saúde mental. Porto Alegre: Sulina, 2012. p. 173-177.

LATOUR, Bruno. Uma sociologia sem objeto? Considerações sobre a Interobjetividade. Traduzido do original "Une sociologie sans objet". Sociologie du travail, p. 587-607, 1994.

. Morale et Technique: la fin des moyens. Artigos on line de Bruno Latour. 1999. Disponível em: <http://www.bruno-latour.fr/sites/default/files/80-RESEAU-FINMOYENpdf.pdf>. Acesso em: 9 set. 2004.

. A esperança de Pandora. Bauru, SP: EDUSC, 2001.

Changer de societé. Refaire de la sociologie. Paris: La Découverte, 2006. 
. Entrevista com Bruno Latour. In: LEMOS, André. A comunicação das coisas. Teoria Ator-Rede e Cibercultura. São Paulo: Annablume, 2013. p. 271-285.

LAW, John. Notes on the Theory of the Actor-Network: Ordering, Strategy and Heterogeneity, $1992 . \quad$ Disponível em: $<$ http://heterogeneities.net/publications/Law1992NotesOnTheTheoryOfTheActorNetwo rk.pdf $>$. Acesso em: 6 jul. 2004.

; MOL, Annemarie. Notes on materiality and sociality. The Sociological Review, v. 4, n. 2, p. 274-294, 1995.

LEAL, Sayonara; BRANT, Sandra. Políticas de inclusão digital no Brasil: a experiência da formação dos monitores dos telecentros GESAC. Liinc em Revista, Rio de Janeiro, v. $8, \quad$ n. $1, \quad$ p. $88-108, \quad 2012$. Disponível em: <http://revista.ibict.br/liinc/index.php/liinc/article/download/463/358>. Acesso em: 13 mar. 2013.

MARASCHIN, Cleci; FRANCISCO, Deise; DIHEL, Rafael. Oficinando em Rede. Oficinas, tecnologias e saúde mental. Porto Alegre: Ed. da UFRGS, 2011.

MORAES, Márcia. Alianças para uma psicologia em ação: sobre a noção de rede. 2003. Disponível em: <http://www.necso.ufrj.br/Ato2003/MarciaMoraes.htm>. Acesso em: 21 set. 2004.

. Do "pesquisarCOM" ou tecer e destecer fronteiras. In: BERNARDES, Anita; TAVARES, Gilead; MORAES, M. (Org.). Cartas para pensar políticas de pesquisa em Psicologia. Vitória: EDUFES, 2014. p. 131-137.

PALOMBINI, Analice; MARASCHIN, Cleci; MOSCHEN, Simone. Tecnologias em Rede. Oficinas de Fazer Saúde Mental. Porto Alegre: Sulina, 2012.

PEREIRA, Vanessa. Entre games e folgações: apontamentos de uma antropóloga na Lan house. Etnográfica, v. 11, n. 2, p. 327-352, 2007.

RODRIGUES, Georgete; SIMÃO, João Batista; ANDRADE, Patrícia. Sociedade da Informação no Brasil e em Portugal: um panorama dos Livros Verdes. Ciências da Informação, Brasília, v. 32, n. 3, p. 89-102, 2003.

SANTAROSA. Lucila. Inclusão digital: espaço possível para pessoas com necessidades educativas especiais. Revista Educação Especial, v. 20, p. 13-30, 2002.

SCALCO, Lúcia. Falakenois: etnografia de um projeto de inclusão digital entre jovens de classes populares em Porto Alegre. 2008. Dissertação (Mestrado). Programa de pós Graduação em Antropologia Social, Instituto de Filosofia e Ciências Humanas da Universidade Federal do Rio Grande do Sul. Porto Alegre, 2008.

. Máquinas, conexões e saberes: o mundo da internet e as práticas de inclusão digital nas classes populares em perspectiva etnográfica. In: CIRCUITO DE DEBATES ACADÊMICOS, 1., 2011. Anais, Brasília, 2012. 
SERRES, Michel. Luzes. Cinco entrevistas com Bruno Latour. São Paulo: Unimarco, 1999.

SILVA, Lawremberg; GUSHKEN, Yuji. Lan house: novos mapas de acesso digital na cidade de Cuiabá. Conexão. Comunicação e cultura UCS, Caxias do Sul, v. 9, n. 18, jul./dez. 2010. Disponível em: $<$ http://www.ucs.br/etc/revistas/index.php/conexao/article/viewFile/619/458>. Acesso em: 31 maio 2010.

SOUZA, Celina. Políticas Públicas: uma revisão da literatura. Sociologias, v. 16, p. 2045, 2006.

VENTURINI, Tommaso. Diving in magma: how to explore controversies with actornetwork theory. Public Understanding of Science XX (XXXX) 1-16. Disponível em: http://www.tommasoventurini.it/wp/wp-content/uploads/2011/08/DivingInMagma.pdf.

Acesso em: 15 de março de 2012

${ }^{i}$ No Livro Verde da Sociedade da Informação no Brasil (BRASIL, 2000, p. 5), são traçadas diretrizes para "[...] alcançar os alicerces de um projeto estratégico, de amplitude nacional, para integrar e coordenar o desenvolvimento e a utilização de serviços avançados de computação, comunicação e informação e de suas aplicações na sociedade brasileira", em consonância com iniciativas de outros países que culminaram com a elaboração dos chamados Livros Verdes (RODRIGUES; SIMÃO; ANDRADE, 2003). Fazem parte desse programa ações como a instalação de Telecentros, disponíveis como centros de inclusão digital para diversos usos (http://www.mc.gov.br/telecentros); e distribuição de laboratórios de informática para as escolas públicas através de projetos como o PROINFO - Programa Nacional de Informática na Educação (http://www.portal.mec.gov.br/index.php?Itemid=462), a partir do qual, convergindo para os mesmos fins, foram deflagradas outras iniciativas como, por exemplo, o PROINFO Integrado, visando à capacitação de professores, o Projeto UCA - Um Computador por Aluno (http://www.fnde.gov.br/programas/programa-nacional-de-tecnologia-educacionalproinfo/proinfo-projeto-um-computador-por-aluno-uca).

ii Tal como em outras escolas, os computadores haviam chegado como parte do investimento governamental nas políticas públicas de inclusão digital e, até aquele momento, permaneciam em caixas por falta de espaço para sua instalação.

iii Os não humanos, para a Teoria Ator-Rede, não se restringem às técnicas ou aos objetos, mas a tudo aquilo que, não sendo humano, contribui para constituir a nossa humanidade. Haraway (2008) amplia essa noção quando destaca os artefatos técnicos e também os animais e outras formas de existência como espécies companheiras dos humanos, aquelas que acompanham para fins diversos e com quem se desenvolvem parcerias variadas. As técnicas já seriam efeitos de misturas, híbridos de humanos e não humanos, mescla de engenho humano e materialidade das coisas (LAW; MOL, 1995).

iv Actante é uma palavra originária da semiótica que, segundo Latour (1994, nota n. 24), "permite ampliar a questão social a todos os seres que interagem numa associação e que intercambiam suas propriedades". Não se limita apenas ao humano como deflagrador das ações, ampliando a capacidade de agência a elementos não humanos e híbridos.

v Atualmente, há dois grupos de egressos da APAE e dois grupos de pré-adolescentes de diferentes Casas Lares, cada um deles frequentando uma oficina por semana. Há duas oficinas disponibilizadas para adultos, funcionários terceirizados dos serviços gerais na universidade. $\mathrm{E}$ há uma oficina semanal para um grupo de idosos, que reúne senhoras de uma comunidade próxima ao campus e albergados numa Instituição de Longa Permanência para Idosos (ILPI). 
vi Em relação à compatibilidade com seus horários de aulas e outros compromissos acadêmicos.

vii Colocando em cena outras possibilidades não dadas em seu início, são interações que fazem fazer, que se performam.

viii Tomam o que já é dado como referência para a repetição e mantêm as definições por inércia.

ix Latour (2006) define um intermediário como aquele que veicula sentido ou força sem provocar transformação; ou seja, definir seus inputs é suficiente para saber seus outputs. Para um mediador, não basta conhecer seus inputs para predizer quais serão os seus efeitos, pois é preciso levar em conta, a cada vez, a sua especificidade. Os mediadores não transportam simplesmente os elementos: eles transformam, traduzem, distorcem e modificam os elementos que transportam.

x Está-se chamando lazer ativo aquele em que os sujeitos, ao invés de consumir passivamente produtos prontos, eles mesmos constroem, traduzem aquilo que lhes cabe (montam e gravam suas próprias listas de músicas, selecionam o que desejam assistir, produzem e divulgam pequenos vídeos em que podem mostrar alguma habilidade ou informação útil para muitos, tornando-se autores/produtores ao invés de simples consumidores).

\section{Sobre os autores}

Maria de Fátima Aranha de Queiroz e Melo é Psicóloga, Psicopedagoga, Mestre em Educação. Doutora em Psicologia Social, Profa. dos cursos de graduação e mestrado em Psicologia da Universidade Federal de São João del Rei, Coordenadora da Brinquedoteca da UFSJ. Endereço eletrônico: fatimaqueiroz.ufsj@gmail.com

Márcia Oliveria Moraes possui graduação em Psicologia pela Universidade Federal Fluminense (1988), mestrado em Psicologia pela Universidade Federal do Rio de Janeiro (1992), doutorado em Psicologia (Psicologia Clínica) pela Pontifícia Universidade Católica de São Paulo (1998) e pós-doutorado em Psicologia Social pela Universidade do Estado do Rio de Janeiro / Lancaster University (2009/2010). Atualmente é Professora Titular do Departamento de Psicologia da Universidade Federal Fluminense, ministrando aulas na graduação e na pós-graduação strito sensu - mestrado e doutorado. Endereço eletrônico:mmoraes@vm.uff.br 